Supplement of Ocean Sci., 14, 1373-1383, 2018

https://doi.org/10.5194/os-14-1373-2018-supplement

(C) Author(s) 2018. This work is distributed under

the Creative Commons Attribution 4.0 License.

(c) (1)

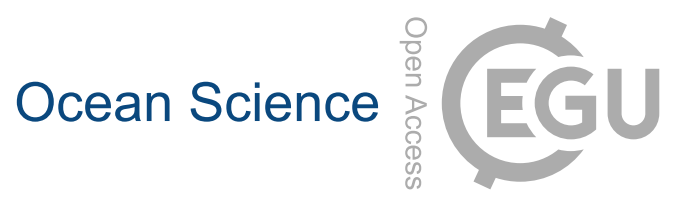

Supplement of

\title{
Modelling of ships as a source of underwater noise
}

Jukka-Pekka Jalkanen et al.

Correspondence to: Jukka-Pekka Jalkanen (jukka-pekka.jalkanen@fmi.fi)

The copyright of individual parts of the supplement might differ from the CC BY 4.0 License. 


\section{SUPPLEMENTARY MATERIAL}

The images presented below are examples of noise source predictions of the Wittekind model used in the main manuscript. Figure S6 illustrates the noise source contributions of high and low frequency cavitation as well as engine noise for a 15000

5 DWT General cargo vessel.

Figure S7a and S7b indicate the impact of the engine mounting parameter of the Wittekind noise model for a container feeder vessel commonly operating in the Baltic Sea area. For resilient engine mounting (S7a), the predicted total noise is lower than for rigid engine mounting (S7b). It should be noted that rigid mounting was assumed for all 2-stroke engines in this work.

10 Figures S8a and S8b include similar predictions for a large bulk cargo vessel and represent a case which falls outside the intended use of the original Wittekind model, but clearly illustrates the impact of engine mounting parameter to noise source description.

Figure S9 and S10 are typical noise source descriptions for RoPax ferries operating the Baltic Sea area. Predicted noise for S9

15 case is a RoPax equipped four main engines and two electric motors driving two Controllable Pitch (CP) propellers. Figure 10 represents a case with four main engines driving two $\mathrm{CP}$ propellers and a reduction gear. 


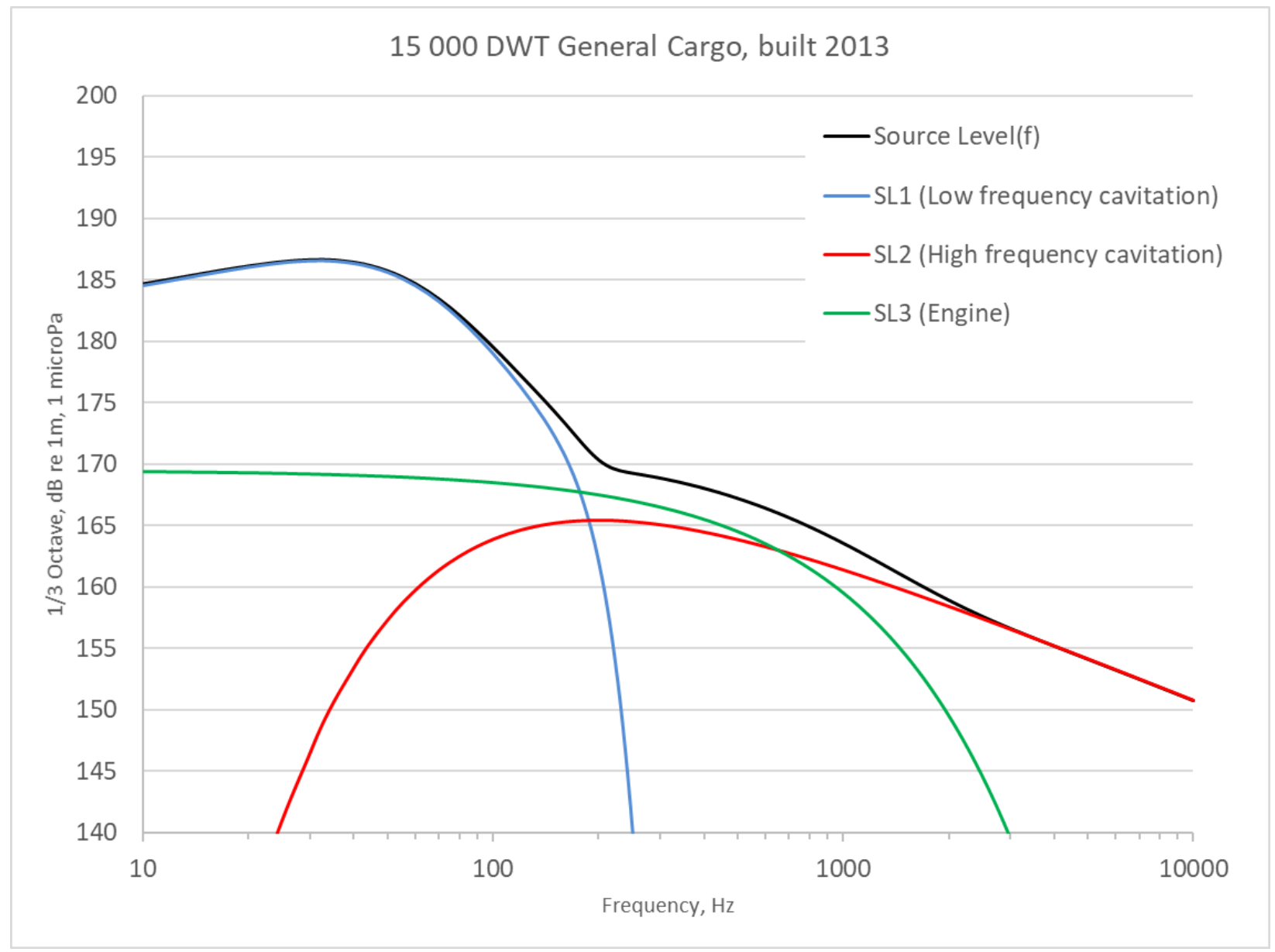

Figure S1 Source levels for a 15000 DWT General Cargo vessel with 4-stroke engine and a FP propeller at design speed of 14.5 knots. 


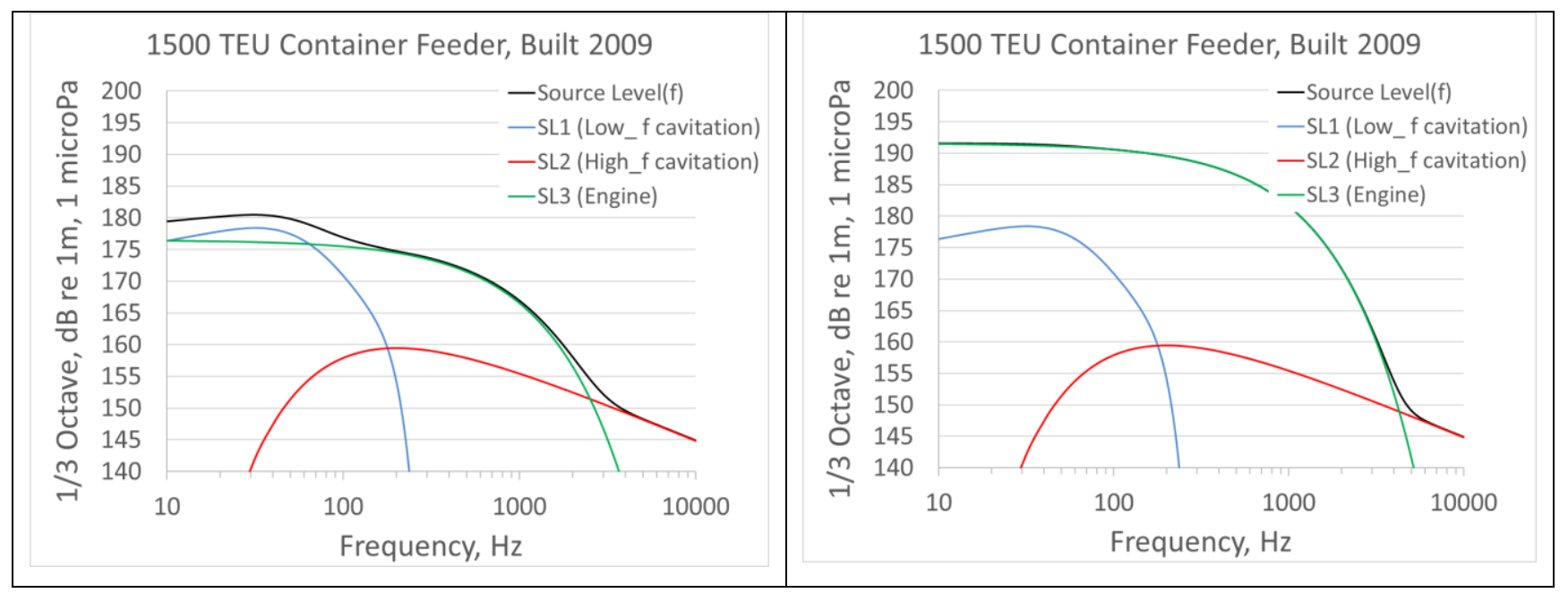

Figure S2 a and b. Noise source levels for a 1500 TEU Container feeder vessel with a 2-stroke engine and a FP propeller assuming flexible mounting (a, left) and rigid mounting (b, right). Vessel traveling at design speed of 19.8 knots

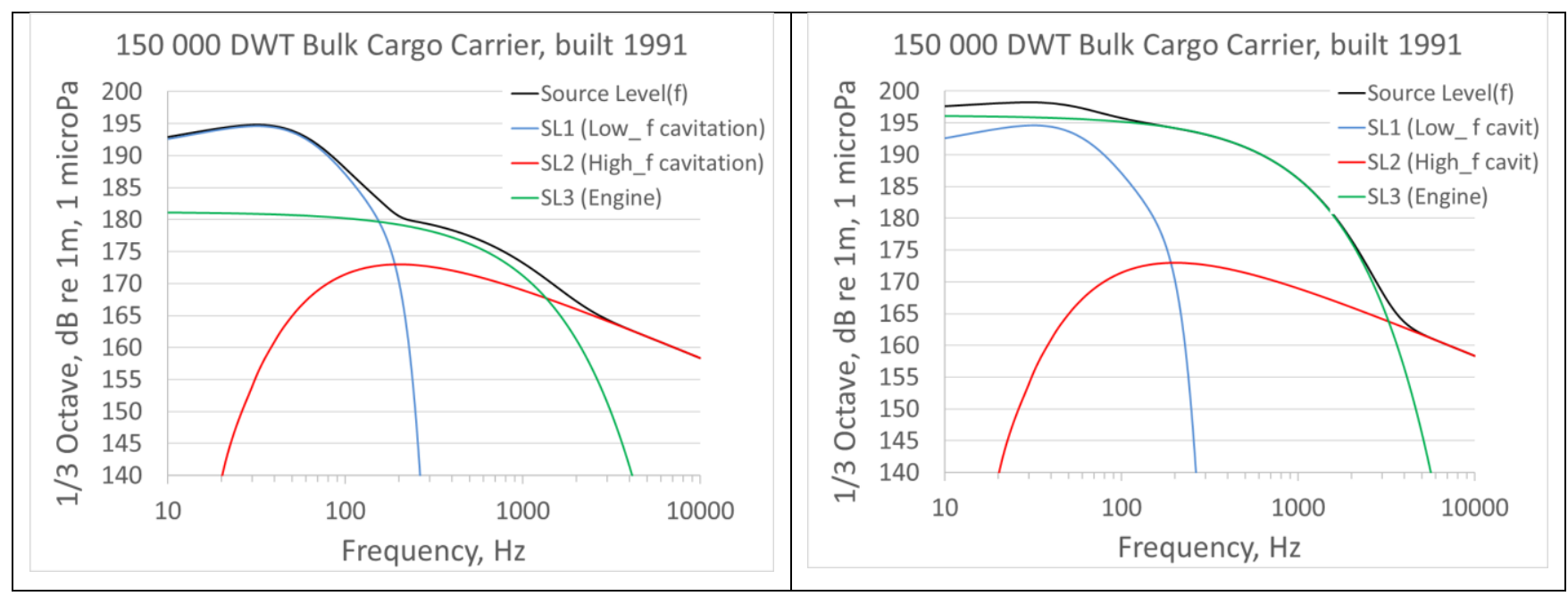

Figure S3a and b. Noise source levels of an 150000 DWT Bulk cargo carrier with a 2-stroke engine with a FP propeller. Source levels estimated assuming flexible mounting (a, left) and rigid mounting (b, right), with vessel traveling at design speed of 13.7 knots. 


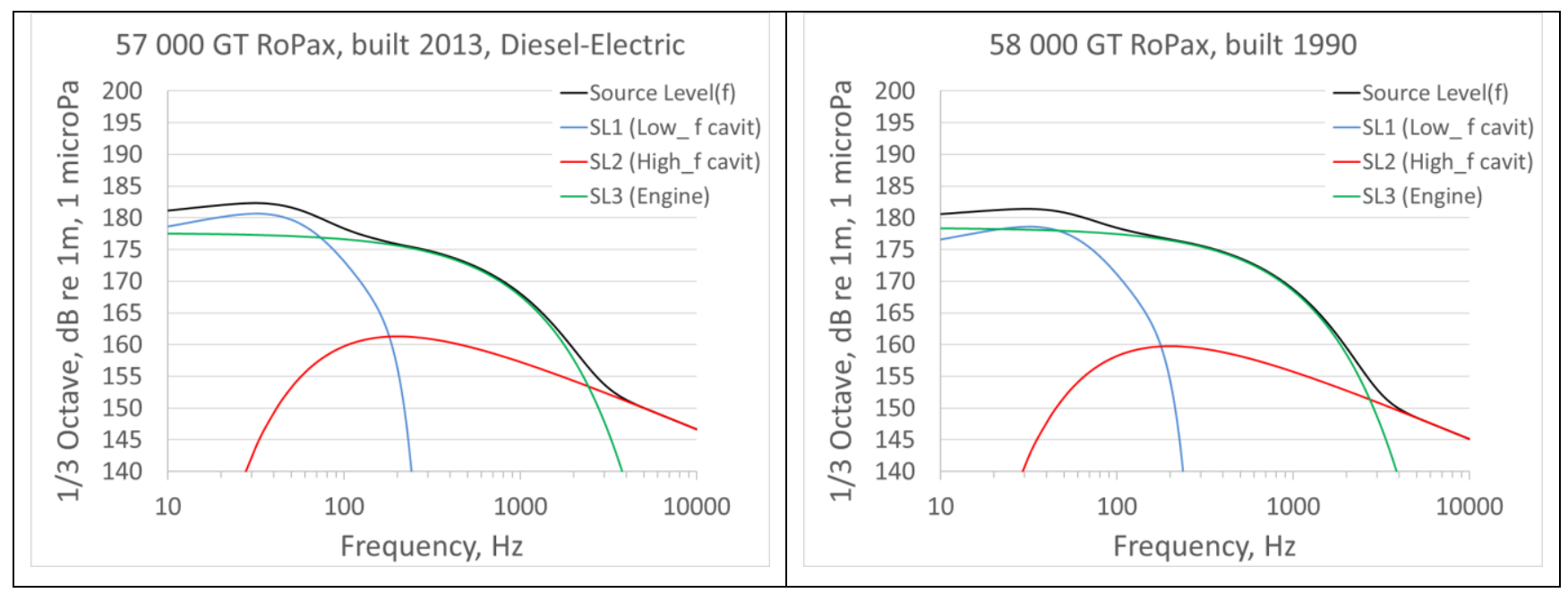

Figures S4 and S10. Noise source levels of a 57000 GT RoPax with four 4-stroke main engines driving two electrical motors with two CP propellers, traveling at design speed 21.8 knots (left) and 58000 GT RoPax, which has four 4-stroke main engines and two CP propellers, at design speed of 21 knots (right). Both cases assume resilient mounting of engines. 